EXTENDED REPORT

\title{
Non-isotopic RNase cleavage assay for mutation detection in MEFV, the gene responsible for familial Mediterranean fever, in a cohort of Greek patients
}

\author{
K Ritis, S Giaglis, N Spathari, A Micheli, D Zonios, D Tzoanopoulos, C C Deltas, S Rafail, R Mean, \\ V Papadopoulos, A G Tzioufas, H M Moutsopoulos, G Kartalis
}

Ann Rheum Dis 2004;63:438-443. doi: 10.1136/ard.2003.009258

See end of article for authors' affiliations

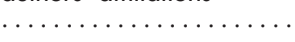

Correspondence to: Dr Konstantinos Ritis, PO BOX 205, 68100 Alexandroupolis, Greece: ritis2@otenet.gr

Accepted 30 June 2003

\begin{abstract}
Background: The MEFV gene is responsible for familial Mediterranean fever (FMF). Several disease associated mutations have been identified. The range of genetic variation in MEFV in Greek patients has not been determined.

Objective: To describe a method that facilitates the routine screening of the entire coding sequence of MEFV (excluding exon 1).

Methods: The non-isotopic RNase cleavage assay (NIRCA) was optimised and used as a first step screening method to screen exons 2 to 10 of MEFV. Exons 2 and 10 were analysed separately at DNA level, while exons 3 to 9 were analysed together at cDNA level. The sample group consisted of 26 FMF patients diagnosed using established clinical criteria, six asymptomatic relatives, 12 patients with atypical clinical manifestations, nine patients suffering from various inflammatory diseases, and three normal individuals. All were analysed by NIRCA for mutations in the MEFV gene and direct sequencing was applied subsequently to confirm the results.

Results: MEFV mutations were identified in 25 of 26 typical FMF patients and in two of 12 patients with atypical manifestations. NIRCA results were in concordance with sequencing findings in all sequences analysed, suggesting that the method is highly reliable in this disease. Sixteen alterations of MEFV were identified (eight missense mutations and eight single nucleotide polymorphisms).

Conclusions: NIRCA can be used for rapid screening of the coding sequence of the MEFV gene in patients suspected of suffering from FMF.
\end{abstract}

$\mathrm{F}$ amilial Mediterranean fever (FMF) is an autosomal recessive disease which mainly affects populations surrounding the Mediterranean basin. ${ }^{1}$ It is characterised by self limiting bouts of fever and painful inflammatory manifestations at one or more sites. There are established clinical criteria that allow the disease to be diagnosed early in its course, ${ }^{1}$ but clinical heterogeneity is common. ${ }^{12}$ The genetic basis of FMF was unknown until 1997, and the diagnosis was largely dependent on the clinical picture. The diagnosis was therefore difficult in patients with mild or atypical forms of the disease. ${ }^{1-3}$

In 1997 the gene linked to FMF, called $M E F V$, was cloned and some of the mutations associated with the disease were identified. ${ }^{45}$ The molecular approach to the diagnosis improved the global identification of the disease. ${ }^{6}$ Since the cloning of $M E F V$, several investigators have continued to screen for disease associated mutations in various ethnic groups. To date about 40 mutations have been described, and the autosomal recessive inheritance of the disease has been established. $^{3}{ }^{3-10}$ The clinical spectrum associated with $M E F V$ mutations extends from the typical manifestations of the full blown disease to the asymptomatic state. This makes the molecular analysis of $M E F V$ a useful tool in clinical practice. ${ }^{23}$ However, the value of the standard molecular approach to FMF diagnosis in populations of mixed ethnic origin with an unclear family history and unknown carrier incidence, or in "non-endemic" countries, remains to be assessed. ${ }^{6-8}$

In an effort to facilitate the transfer of molecular testing from research to diagnostic laboratories, several screening methods have been developed. ${ }^{3-9}{ }^{11}$ However, the large size of the $M E F V$ coding region (around 2400 base pairs (bp)) and the diversity of the genetic alterations ${ }^{10}$ make the routine screening of the entire sequence of the $M E F V$ gene difficult, particularly in groups with an unknown spectrum of genetic alterations. Such diagnostic techniques are therefore restricted to those capable of detecting known and common mutations. $^{3}$

Our aim in the present study was to develop a convenient and reliable method for analysing mutations in the entire coding region (excluding exon 1) of the $M E F V$ gene at the DNA or cDNA level, using the non-isotopic RNase cleavage assay (NIRCA). ${ }^{12}{ }^{13}$ The technique was subsequently applied in a cohort of Greek patients of varying ethnic origins with an unknown spectrum of $M E F V$ alterations and unknown carrier status.

\section{METHODS \\ Patients}

Twenty six FMF patients originating from 20 unrelated families and diagnosed by established clinical criteria were analysed for $M E F V$ mutations over the entire coding sequence. Clinical and demographic data are given in table 1. Six asymptomatic relatives of these patients and three normal individuals were also studied. Twelve patients with atypical manifestations were included in the studyfour with Still's disease, three with fever of unknown origin (FUO), and five with recurrent serositis. Control samples

Abbreviations: FMF, familial Mediterranean fever; NIRCA, nonisotopic RNase cleavage assay; SNP, single nucleotide polymorphism 


\begin{tabular}{|c|c|c|c|c|c|c|c|c|c|}
\hline \multirow{2}{*}{$\begin{array}{l}\text { Patient } \\
\text { No }\end{array}$} & \multirow[b]{2}{*}{$\mathrm{Age}^{*} / \operatorname{sex}$} & \multirow{2}{*}{$\begin{array}{l}\text { Age of onset } \\
\text { (years) }\end{array}$} & \multirow[b]{2}{*}{ FMF criteria† } & \multirow[b]{2}{*}{ Origin } & \multirow{2}{*}{$\begin{array}{l}\text { Family } \\
\text { history }\end{array}$} & \multicolumn{3}{|c|}{ NIRCA digestion } & \multirow[b]{2}{*}{9 Sequencing (amino acid alteration) } \\
\hline & & & & & & Exon 10 & Exon 2 & Exons 3-9 & \\
\hline 1 & $14 \%$ & 3 & $1 \mathrm{M}, 2 \mathrm{~m}$ & Greekł‡ & Pos§§ & Pos & Neg & Neg & M680I/V726A \\
\hline 2 & 17 ơ & 9 & $2 \mathrm{M}, 1 \mathrm{~m}$ & Greekł‡ & Neg & Pos & Neg & NP & M694V/M694V \\
\hline 3 & 15 ф† & 4 & $2 \mathrm{M}, 1 \mathrm{~m}$ & Greekł‡ & Neg & Pos & Neg & Neg & M694V/ M694V \\
\hline 4 & 32 \& & 10 & $2 M, 2 m$ & Greek㧊 & Neg & Pos & Pos & Pos & $\begin{array}{l}\text { M694V/0, D102D/D102D, G138G/G138G, A165A/ } \\
\text { A165A, G219G/0, R314R/O, E474E/O, D510D/0 }\end{array}$ \\
\hline 5 & 40 ф§ & 8 & $2 M, 2 m$ & Greekł‡ & Neg & Pos & Neg & NP & M694V/M694I \\
\hline 6 & 38 ○ई & 12 & $2 M, 2 m$ & Greekł‡ & $\mathrm{Neg}$ & Pos & $\mathrm{Neg}$ & $\mathrm{Neg}$ & M694V/M694I \\
\hline 7 & $31 \%$ & 9 & $2 \mathrm{M}, 1 \mathrm{~m}$ & Greek & Neg§§ & Pos & $\mathrm{Neg}$ & Neg & M680I/M694V \\
\hline 8 & $70^{\circ}$ & 6 & $1 \mathrm{M}, 1 \mathrm{~m}$ & Greek & Neg & Pos & $\mathrm{Neg}$ & Neg & V726A $/ 0$ \\
\hline 9 & $280^{\circ}$ & 14 & $2 M$ & Greek & Neg & Pos & $\mathrm{Neg}$ & Neg & $M 694 \mathrm{~V} / 0$ \\
\hline 10 & $270^{\circ}$ & 24 & $1 \mathrm{M}, 2 \mathrm{~m}$ & Greekł‡ & Neg & Neg & Neg & Neg & Absence of alterations \\
\hline 11 & $45 \mathrm{o}^{\circ}$ & 5 & $2 \mathrm{M}, 1 \mathrm{~m}$ & Jewish & Neg§§ & Pos & $\mathrm{Neg}$ & Neg & M694V/M694V \\
\hline 12 & 12 \% & 4 & $2 \mathrm{M}, 1 \mathrm{~m}$ & Jewish & Pos & Pos & $\mathrm{Neg}$ & Neg & M694V/M694V \\
\hline 13 & 16 on & 9 & $2 \mathrm{M}, 1 \mathrm{~m}$ & Jewish & Pos & Pos & $\mathrm{Neg}$ & NP & M694V/R761H \\
\hline 14 & $17 \%$ & 3 & $2 \mathrm{M}, 1 \mathrm{~m}$ & Armenian & Neg & Neg & Pos & Pos & $\begin{array}{l}\text { R202Q/R202Q, D102D/D102D, G138G/G138G, } \\
\text { A165A/A165A R314R/O, E474E/0, Q476Q/0, } \\
\text { D510D/0 }\end{array}$ \\
\hline 15 & $5 \%$ & 4 & $2 \mathrm{M}, 1 \mathrm{~m}$ & Greek & $\mathrm{Neg}$ & $\mathrm{Neg}$ & Pos & $\mathrm{Neg}$ & $\begin{array}{l}\text { R202Q/R202Q, D102D/D102D, G138G/G138G, } \\
\text { A165A/A165A }\end{array}$ \\
\hline 16 & $26 \%$ & 12 & $2 \mathrm{M}, 1 \mathrm{~m}$ & Greek & $\mathrm{Neg}$ & Neg & Pos & Neg & R202Q/R202Q, D102D/D102D \\
\hline 17 & $18 \%$ & 8 & $1 \mathrm{M}, 2 \mathrm{~m}$ & Greek & Neg & Neg & Pos & Neg & E148Q/E148Q \\
\hline 18 & 4 o** & 3 & $1 \mathrm{M}, 2 \mathrm{~m}$ & Greekł‡ & Pos & Pos & Pos & NP & M680I/0, E167D/0, D102D/0 \\
\hline 19 & 28 q** & 12 & $2 M$ & Greekł‡ & Neg & Pos & Pos & Neg & M680I/0, E167D/O, D102D/0, R202Q/0 \\
\hline 20 & 22 १†† & 4 & $2 \mathrm{M}, 1 \mathrm{~m}$ & Greekł‡ & Pos & Pos & $\mathrm{Neg}$ & NP & M680I/M694V \\
\hline 21 & 18 p†t & 8 & $1 \mathrm{M}, 2 \mathrm{~m}$ & Greekł‡ & Pos & Pos & $\mathrm{Neg}$ & NP & M680I/M694V \\
\hline 22 & 55 ơ†† & 12 & $3 m$ & Greekł‡ & Neg & Pos & $\mathrm{Neg}$ & Neg & $M 694 \mathrm{~V} / 0$ \\
\hline 23 & $24 \circ^{\circ}$ & 10 & $2 \mathrm{M}, 1 \mathrm{~m}$ & Greekł‡ & Neg & Pos & $\mathrm{Neg}$ & Neg & M680I/V726A \\
\hline 24 & $17 \%$ & 12 & $2 M$ & Greek & $\mathrm{Neg}$ & Pos & $\mathrm{Neg}$ & $\mathrm{Neg}$ & M680I/M694V \\
\hline 25 & $200^{\circ}$ & 14 & $2 \mathrm{M}, 1 \mathrm{~m}$ & Greek & Neg & $\mathrm{Neg}$ & Pos & Neg & $\begin{array}{l}\text { R202Q/R202Q, D102D/D102D, G138G/G138G, } \\
\text { A165A/A165A }\end{array}$ \\
\hline 26 & $190^{\circ}$ & 12 & $2 M$ & Greek & Neg & Pos & Pos & $\mathrm{Neg}$ & $M 694 \mathrm{~V} / 0, \mathrm{R} 202 \mathrm{Q} / 0$ \\
\hline
\end{tabular}

*Age in years corresponding to the age when genetic screening was done.

tDiagnostic criteria according to Livneh et al ': $M$, major criteria; $m$, minor criteria

$\ddagger \S$ ** $+†$ Patients with the same symbol are relatives.

$\ddagger \ddagger T$ The parents of these patients were refugees from Asia Minor.

$\S \S$ Overall, six asymptomatic relatives of these patients were studied.

FMF, familial Mediterranean fever; Neg, negative; NIRCA, non-isotopic RNase cleavage assay; NP, not performed; Pos, positive.

were obtained from nine patients suffering from various other known types of inflammatory disease (four with rheumatoid arthritis, two with systemic lupus erythematosus, and three with vasculitis)

\section{DNA and RNA extraction, cDNA synthesis}

Peripheral blood mononuclear cells (PBMC) were separated by density gradient centrifugation (lymphocyte separation medium, Gibco-BRL, Life Technologies, Paisley, UK). The DNA extraction protocol has been described previously. ${ }^{14}$ Total RNA for polymerase chain reaction (PCR) was extracted from $5 \times 10^{6}$ PBMC using TRIzol (Gibco-BRL /Life Technologies). cDNA synthesis was done using $1 \mu \mathrm{g}$ of extracted RNA and 20 units AMV reverse transcriptase (Promega, Milwaukee, Wisconsin, USA) according to the manufacturer's instructions.

\section{Polymerase chain reaction}

Appropriate templates for in vitro transcription using the T7 and SP6 RNA polymerases were generated by PCR. MEFV gene amplification was done in three fragments corresponding to exon 2, exon 10, and exons 3 to 9, respectively. Exons 2 and 10 were amplified using DNA as template, while exons 3 to 9 were amplified at the cDNA level. A nested PCR was also applied separately for every fragment. The sequences of T7 and SP6 promoters constituted the $5^{\prime}$ end of the sense and antisense nested primers, respectively. Thus the nested PCR products contained the T7 and SP6 phage promoters and under suitable conditions, using the corresponding polymerases, synthesis of microgram amounts of RNA was achieved with the PCR product as template. All primers were designed with the aid of the Oligo-5 software (NBI, Plymouth, Minnesota, USA). The sequences of primers and the conditions applied for the primary and nested PCRs used for the amplification the three $M E F V$ fragments are shown in table 2 .

\section{Non-isotopic RNase cleavage assay}

The principle of this method has been described previously. ${ }^{1213}$ The assay was done using the MutationScreener kit (Ambion, Austin, Texas, USA) with some modifications. To provide the wild type control required for NIRCA, three healthy individuals were directly sequenced in exons 2 to 10.

In principle a sense RNA product generated from a wild type control template, using the appropriate RNA polymerase, was hybridised separately with the antisense RNA strand generated from either the same template (as the nonmutated control) or the template generated from the patient with suspected FMF. The opposite combination-that is, hybridisation using the antisense strand of the wild type with the sense strand generated from the patient's RNA-was also employed. In addition, sense and antisense RNA strands generated from each patient were hybridised to each other. Thus for each patient a group of four RNA duplexes was generated and was subsequently available for RNase digestion. For every $10 \mu \mathrm{l}$ of transcription reaction, $1-4 \mu \mathrm{l}$ of nested PCR product was used. This volume of transcription 
Table 2 DNA and cDNA amplification of MEFV: primer sequences and conditions for the polymerase chain reaction

\begin{tabular}{|c|c|c|c|c|}
\hline $\begin{array}{l}\text { Amplified DNA or cDNA } \\
\text { sequence }\end{array}$ & Name and sequence of primers & Primer positions* & PCR product & PCR conditionst \\
\hline \multirow[t]{2}{*}{ DNA amplification EXON 2} & $\begin{array}{l}\text { M2U 5'AACTTTAATATCCAAGGGGATTC 3' } \\
\text { M2L 5' TCTCTGCAGCCGATATAAAGTA 3' }\end{array}$ & $\begin{array}{l}2710-2732 \\
3458-3480\end{array}$ & $771 \mathrm{bp}$ & $\begin{array}{l}\text { Primary PCR: } \mp \text { Denaturation at } 94^{\circ} \mathrm{C} \text { for } 8 \mathrm{~min} \\
\text { followed by } 37 \text { cycles of denaturation at } 94^{\circ} \mathrm{C} \\
\text { for } 80 \mathrm{~s} \text {, annealing at } 58^{\circ} \mathrm{C} \text { for } 60 \mathrm{~s} \text {, and } \\
\text { extension at } 72^{\circ} \mathrm{C} \text { for } 60 \mathrm{~s}\end{array}$ \\
\hline & $\begin{array}{l}\text { T2U§ 5' CTCTCCTCTGCCCTGAA 3' } \\
\text { SP6MEFV2§ 5' GGTGACCGAATGTTCTGG 3' }\end{array}$ & $\begin{array}{l}2734-2750 \\
3421-3438\end{array}$ & $745 \mathrm{bp}$ & $\begin{array}{l}\text { Nested PCR: } \neq \text { Denaturation at } 94^{\circ} \mathrm{C} \text { for } 8 \mathrm{~min} \\
\text { followed by } 37 \text { cycles of denaturation at } 94^{\circ} \mathrm{C} \\
\text { for } 80 \mathrm{~s} \text {, annealing at } 60^{\circ} \mathrm{C} \text { for } 60 \mathrm{~s} \text {, and } \\
\text { extension at } 72^{\circ} \mathrm{C} \text { for } 60 \mathrm{~s} \text {. For nested PCR, } \\
1-2 \mu \text { of primary product was used as } \\
\text { template }\end{array}$ \\
\hline \multirow[t]{2}{*}{ DNA amplification EXON } & $\begin{array}{l}\text { 10U 5' GATTGGCGCTCAGGCACAT 3' } \\
\text { 10L 5' GGCTCCGTGGGCACAGTAAC 3' }\end{array}$ & $\begin{array}{l}13709-13727 \\
14569-14588\end{array}$ & $880 \mathrm{bp}$ & $\begin{array}{l}\text { Primary PCR: Denaturation at } 94^{\circ} \mathrm{C} \text { for } 3 \mathrm{~min} \\
\text { followed by } 25 \text { cycles of denaturation at } 94^{\circ} \mathrm{C} \\
\text { for } 60 \mathrm{~s} \text {, annealing at } 59^{\circ} \mathrm{C} \text { for } 60 \mathrm{~s} \text {, and } \\
\text { extension at } 72^{\circ} \mathrm{C} \text { for } 60 \mathrm{~s}\end{array}$ \\
\hline & $\begin{array}{l}\text { 10T7U§ 5' TGTGCTCTCCCCTACCA 3' } \\
\text { MEFVSP6§ 5' CACCTAGTCGGCATTC 3' }\end{array}$ & $\begin{array}{l}13777-13793 \\
14517-14533\end{array}$ & $797 \mathrm{bp}$ & $\begin{array}{l}\text { Nested PCR: Denaturation at } 94^{\circ} \mathrm{C} \text { for } 3 \mathrm{~min} \\
\text { followed by } 23 \text { cycles of denaturation at } 94^{\circ} \mathrm{C} \\
\text { for } 60 \mathrm{~s} \text {, annealing at } 59^{\circ} \mathrm{C} \text { for } 60 \mathrm{~s} \text {, and } \\
\text { extension at } 72^{\circ} \mathrm{C} \text { for } 60 \mathrm{~s} \text {. } 9 \text { For nested PCR, } \\
0.5-2 \mu \mathrm{l} \text { of primary product was used as } \\
\text { template }\end{array}$ \\
\hline \multirow[t]{2}{*}{$\begin{array}{l}\text { cDNA amplification EXONS } \\
3 \text { to } 9\end{array}$} & $\begin{array}{l}\text { 39U 5' AAAAGACAGCTGCGAATCTG 3' } \\
\text { 39L 5' CCTCTCCCATTITITCC 3' }\end{array}$ & $\begin{array}{l}\text { c835-c854 } \\
\text { c1907-c1925 }\end{array}$ & $1091 \mathrm{bp}$ & $\begin{array}{l}\text { Primary PCR: Denaturation at } 94^{\circ} \mathrm{C} \text { for } 3 \text { min } \\
\text { followed by } 35 \text { cycles of denaturation at } 94^{\circ} \mathrm{C} \\
\text { for } 80 \mathrm{~s} \text {, annealing at } 60^{\circ} \mathrm{C} \text { for } 80 \mathrm{~s} \text {, and } \\
\text { extension at } 72^{\circ} \mathrm{C} \text { for } 80 \mathrm{~s} ; 4 \mu \text { of generated } \\
\text { cDNA was used as template }\end{array}$ \\
\hline & $\begin{array}{l}\text { T39U§ 5' AGCTGCGAATCTGGAC 3' } \\
\text { SP39L§ 5' AAGATGAGGTGGGGTAA 3' }\end{array}$ & $\begin{array}{l}\text { c842-c857 } \\
\text { c1862-c1879 }\end{array}$ & 1078 bp & $\begin{array}{l}\text { Nested PCR: Denaturation at } 94^{\circ} \mathrm{C} \text { for } 3 \mathrm{~min} \\
\text { followed by } 35 \text { cycles of denaturation at } 94^{\circ} \mathrm{C} \\
\text { for } 80 \mathrm{~s} \text {, annealing at } 60^{\circ} \mathrm{C} \text { for } 80 \mathrm{~s} \text {, and } \\
\text { extension at } 72^{\circ} \mathrm{C} \text { for } 80 \mathrm{~s} ; 1 \mu \text { of primary } \\
\text { product was used as template }\end{array}$ \\
\hline
\end{tabular}

*The nucleotide position corresponds to the DNA and cDNA of MEFV accession sequences AF 111163 and AF 018080 , respectively.

†All reactions were carried out in $50 \mu$ volume using 2.5 units of platinum Taq DNA polymerase (Gibco), 50 pmol of each primer, 200 mmol of each deoxyribonucleotide triphosphate, and $1.5 \mathrm{mmol}$ of $\mathrm{MgCl}_{2}$.

$\$ 10 \%$ DMSO was added in the reaction mixture.

§T2U, 10T7U, T39U, and SP6MEFV2, MEFVSP6, SP39L primers have at the 5' end the T7 and SP6 promoter sequences, respectively (T7: 5'

TAATACGACTCACTATAGGG 3' and SP6: 5' ATTTAGGTGACACTATAGGA 3').

'Nested PCR products were used for NIRCA analysis.

bp, base pairs; NIRCA, non-isotopic RNase cleavage assay; PCR, polymerase chain reaction.

reaction is sufficient to generate $20 \mu$ of hybridisation reaction for every group of RNA duplex. All in vitro transcription and hybridisation reactions were carried out according to the manufacturers' instructions (Promega and Ambion, respectively).

The optimal RNase dilution used in the final step of the procedure depends on the quantity of RNA hybrids generated. Routinely, in order to obtain the optimal cleavage, $4 \mu \mathrm{l}$ of each RNA hybrid group among the four RNA duplexes for every patient were digested separately with RNase 1 (1/80), RNase Tl (1/40), and mixed 1/l RNase 1 and RNase Tl in the same dilutions. Digestion products of each RNA hybrid were always checked in comparison with wild type RNA hybrid, which was digested with the same RNase. Cleavage products were detected on $1.5 \%$ agarose gel. Gel documentation was done using a Kodak DC120 digital camera. All digestion reactions followed the manufacturer's instructions (Ambion). The results of typical digestion experiments in the three fragments of $M E F V$ are shown in fig 1.

\section{Sequencing}

Either an Exo (-) Pfu cyclist DNA sequencing kit (Stratagene, La Jolla, California, USA) or the MWG Biotech AG sequencing service (http://www.mwgdna.com) was used for direct sequencing analysis of the $M E F V$ PCR products.

Direct sequencing in the two PCR fragments corresponding to exons 2 and 10 was undertaken in all FMF patients. Based on the picture observed after the analysis by NIRCA, the known clinical profiles, and the sequencing results in exons 2 and 10, an additional sequencing analysis of exons 3 to 9 was done in the following subjects (table 1): in patients 14, 15, 16, and 25 with R202Q/R202Q; in patient 10, in whom NIRCA analysis was negative; in patient 4 , in whom NIRCA revealed digestion products in all three PCR fragments; and in heterozygous patients $8,9,22$, and 26 . Sequencing reactions in exons 2 to 10 were also done in four of the 12 patients with atypical FMF where NIRCA was positive in at least one fragment. Asymptomatic relatives were sequenced only in those PCR fragments where NIRCA analysis was positive.

\section{R202Q analysis}

In order to control the incidence of R202Q alteration, nested PCR products of exon 2 (table 2 ) originating from 60 healthy individuals (inhabitants of north eastern Greece, with a family history of FMF) were digested with the PvuII restriction enzyme (Invitrogen, Paisley, UK), which selectively cleaves the mutated sequence at the 202 site (GAC $\downarrow$ GTC), replacing the 745 bp PCR product with three fragments of 412, 206, and $127 \mathrm{bp}$. Selectively, according to R202Q status, 15 of 60 healthy individuals were analysed by NIRCA in exon 10 and 2. Homozygosity versus nonhomozygosity of R2020Q was evaluated in both FMF patients and a group of 60 normal individuals using $\chi^{2}$ testing with Yates' correction for small expected values. ${ }^{16}$

\section{RESULTS \\ NIRCA results}

Characteristic positive digestion products were identified in 25 of the 26 patients in table 1. Among the 25 NIRCA positive patients, 16 showed digestion products in exon 10, and four others in exon 2 . Three patients $(18,19$, and 26) were positive in both exons 10 and 2, while patient 14 was positive by 


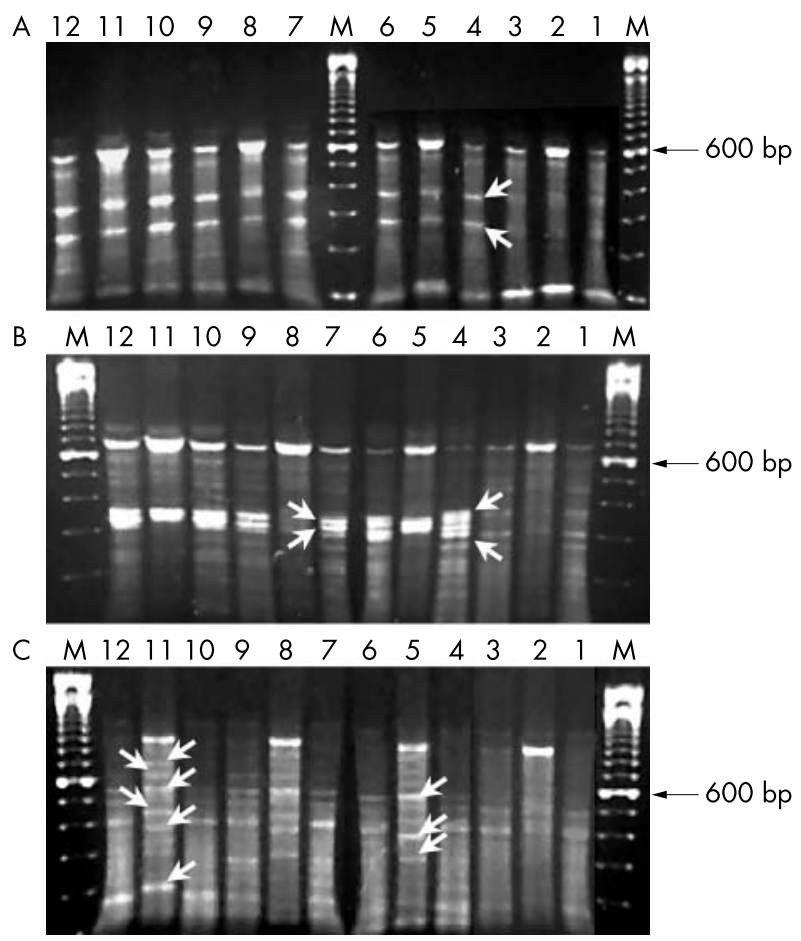

Figure 1 Non-isotopic RNase cleavage assay (NIRCA) digestion profiles in the three separated fragments. Typical digestion profiles of exon 10 (A), exon 2 (B), and exons 3-9 (C). (A) Patient 19, E167D/0.(B) Patient 24, M694V/M680I. (C) Patient 14 with multiple digestion products (lanes 5, 8, and 11) indicating a variety of SNPs: R314R/0, E474E/0, Q476Q/0, and D510D/0. In all gels, lanes 1, 2, and 3 correspond to RNA duplex originated after hybridisation of wild type sense and antisense strands digested with RNase 1 (1/80), RNase T1 (1/40), and mixed 1/1 RNase 1 and RNase T, respectively. Lanes 4, 5, and 6 correspond to RNA duplex originated after hybridisation of patient T7 and wild type SP6 opposable strands, digested with the same combination of RNases as above. Lanes 7, 8, and 9 correspond to RNA duplex originated after hybridisation of patient SP6 and wild type T7 opposable strands, digested with the same combination of RNases as above. Lanes 10, 11, and 12 correspond to RNA duplex originated after hybridisation of patient sense and antisense strands, digested as the wild type RNA duplex. The last three lanes (10, 11, and 12) help to define heterozygosis and are not necessary for the detection of mutations. Arrows indicate the digestion products. M, 100 base pair DNA marker (Gibco).

NIRCA in exon 2 and the region between exons 3 and 9 . Finally, patient 4 revealed cleavage products in all three PCR fragments. NIRCA analysis in the six asymptomatic relatives showed digestion products similar to those found in affected members of the family. All patients suffering from the other inflammatory diseases and the three normal individuals were negative by NIRCA mutational analysis. Of 12 patients with atypical manifestations of FMF, one had digestion products in exon 10, two in exon 2, and one in exons 3 to 9.

\section{Sequencing results confirmed NIRCA findings}

Positive and negative fragments identified by NIRCA and subsequently directly sequenced were in accordance when analysed. The sequencing details are shown in table 1. Typical digestion profiles corresponding to certain mutations are also indicated in fig $2 \mathrm{~B}$. Sequence data from the coding region in four of 12 patients with atypical FMF disease were also in agreement with the positive NIRCA results. Thus in one patient, positive in exon 2 and characterised as Still's disease, the D102D/0, G138G/0, and A165A/0 SNPs were identified. Another patient, also characterised as Still's disease, was M694V heterozygous. In one patient who was positive in exon 2 and had been diagnosed earlier as recurrent polyserositis, the R202Q/R202Q alteration and D102D/ D102D, G138G/G138G, A169A/A169A, and G219G/0 SNPs were found. Finally, in one patient with FUO, who showed digestion products in exons 3 to 9, the E474E/0, Q476Q/0, and D510D/0 SNPs were identified.

\section{R202Q homozygosity in FMF patients}

Homozygosity of R202Q alteration was detected in four of the 26 FMF patients $(14,15,16$, and 25 in table 1) in whom direct sequencing of exons 2 to 10 was negative for other mutations. None of 60 healthy individuals was found to be homozygous for R202Q, and a statistically significant result $(p=0.007)$ was observed in comparison with the FMF patients. In addition, one of 12 patients with atypical manifestations was R202Q homozygous. R202Q heterozygosity was observed in 15 of 60 healthy individuals and in patients 19 and 26 in table 1 (data not shown). The 15 R202Q healthy heterozygous individuals were negative by NIRCA in exon 10, while in two of these, a similar digestion pattern to the D102D alteration was observed.

\section{DISCUSSION}

The diagnosis of FMF has until recently relied on clinical signs alone, thus making it difficult to establish a correct diagnosis in patients with mild or atypical manifestations of the disease. ${ }^{12}$ The isolation of the $M E F V$ gene and the identification of the mutations causing FMF opened the way for direct molecular diagnosis and genotype-phenotype correlations. ${ }^{3}$ Various studies have now shown that the spectrum of disease associated signs is broader than previously believed. ${ }^{23} 7$ For technical reasons the routinely used methods have often focused on known and common mutations of $M E F V .^{3}$ The application of methods providing routine genetic screening of the entire $M E F V$ sequence is expected to improve the early and correct diagnosis of FMF even further, thus allowing more accurate genotype-phenotype correlation. ${ }^{3}{ }^{6}$

In the present study we optimised NIRCA as a primary method of screening the entire coding region of $M E F V$ (excluding exon 1). The reliability of the technique was confirmed by direct sequencing. From our NIRCA and sequencing findings we suggest that it is safe not to undertake sequencing in those products where NIRCA digestion is negative for all RNA duplexes. Thus NIRCA may constitute an alternative method for reliable screening in patients suspected of having FMF and who are negative for $M E F V$ mutations after restriction enzyme analysis. Furthermore, this method could be applied as a primary screening technique in populations where the incidence and spectrum of mutations, as well as the "endemic" character of FMF, have not been established. ${ }^{17}$ NIRCA is also relatively rapid and low cost in terms of materials and equipment required. In everyday use, application of NIRCA is recommended in exon 10 and 2 at first, and subsequently in exons 3 to 9, provided that mutational analysis in exon 10 or 2, or both, is not sufficient to explain the FMF phenotype. Although recent studies in Hellenic populations from Greece $^{18}$ and Cyprus ${ }^{11}$ have shown some common mutations of $M E F V$ in FMF patients, the application of NIRCA allowed us to identify a broader spectrum of alterations consisting of eight missense mutations and eight SNPs (table 1, fig 2A). This approach failed to detect mutations in only one among 26 typical FMF patients. In addition, in a group of 12 patients with atypical manifestations of FMF, mutations of $M E F V$ were identified in two. We suggest that the application of NIRCA improves the genetic identification of FMF.

Two particular technical difficulties appeared during the optimisation of this method. The first problem was the 
A

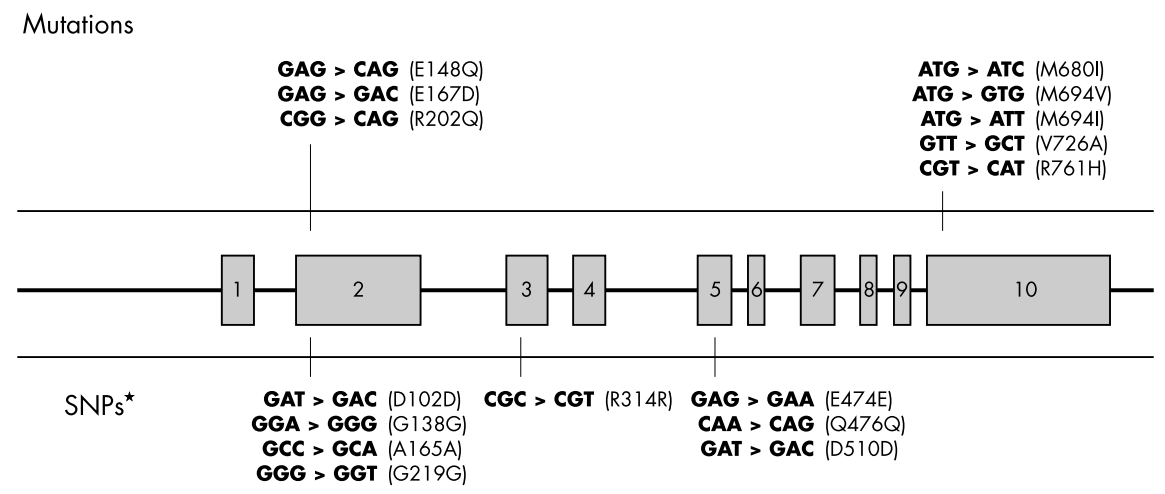

B

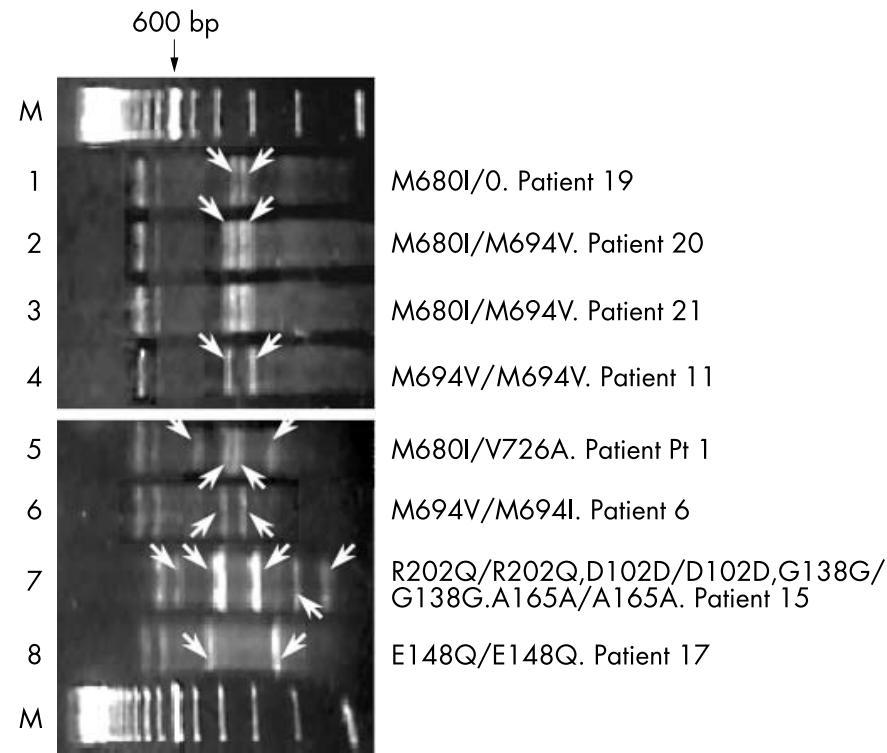

Figure 2 Schematic presentation of genetic alterations and digestion pattern of the commonly identified mutations. (A) Presentation of identified genetic alterations according to their location on MEFV. ${ }^{*}$ These polymorphisms have also been described (http://fmf.igh.cnrs.fr/infevers/search/ search.pl? maladie =FMF), except the GGC $>219>$ GGT. (B) Summarised typical digestion patterns corresponding to certain MEFV mutations identified in some of the patients in table 1. Arrows indicate the digestion products. M, 100 base pair DNA marker (Gibco); SNP, single nucleotide polymorphism.

effective amplification of the GC rich sequence of exon 2. Various nested primers with sequences of T7 and SP6 promoters at the $5^{\prime}$ end were designed and used. The best amplification was obtained using the primer set T2U and SP6MEFV2 (table 2). The antisense primer (SP6MEFV2) of this set is complementary to the last 18 nucleotides at the $3^{\prime}$ end of exon 2, resulting in failure to detect alterations in the last 40 nucleotides ( $\sim 15$ amino acids) of this exon by NIRCA. However, this same region of exon 2 is screened during the amplification and mutational analysis of exons 3 to 9, where the set of nested primers T39U and S39L (table 2) can amplify the last $90 \mathrm{bp}$ at the $3^{\prime}$ end of exon 2. We have also omitted exon 1 from the PCR-NIRCA experimental strategy in an effort to simplify the procedure, bearing in mind that only one mutation in a single patient has been described to date. ${ }^{30}$ In addition, fragments less than $400 \mathrm{bp}$ (the length of exon 1 is $270 \mathrm{bp}$ ) or more than $1200 \mathrm{bp}$ are not recommended for NIRCA analysis. ${ }^{12} 1315$

Another technical problem in some patients was the presence of additional smaller bands with the main PCR product during the amplification of exons 3 to 9. These smaller bands are caused by the skipping of different exons between exons 2 and 10 (data not shown). This problem can easily be overcome if the selected sense and antisense strands of healthy individuals for in vitro transcription and hybridisation contain only the main PCR product. ${ }^{12} 1315$

The homozygous alteration R202Q/R202Q was identified in four FMF patients $(14,15,16$, and 25 in table 1$)$ and in one patient with atypical manifestations (recurrent serositis). Although, R202Q has previously been considered a polymorphism, ${ }^{9}$ there is some evidence suggesting that R202Q homozygosity constitutes a pathogenic genetic event in FMF. The absence of other mutations at the coding region of $M E F V$, the favourable response to colchicine in all five patients, and finally the lack of this homozygous alteration in 60 healthy individuals and nine patients suffering from other inflammatory diseases raise serious suspicions about the possible mutational role of $\mathrm{R} 202 \mathrm{Q} / \mathrm{R} 202 \mathrm{Q}$ in $M E F V$. Although $\mathrm{R} 202 \mathrm{Q} / 0$ heterozygosity is quite common among healthy individuals, its homozygosity in FMF patients may reflect a "dosage depended" deleterious effect. Future functional studies and the determination of the three dimensional 
structure of the pyrin protein may assist in resolving this uncertainty.

There are geographical regions, mainly in the Mediterranean basin, where the prevalence of FMF is not well characterised. Furthermore, there is still much to be learned regarding the genotype-phenotype correlations in this disease. The application of the NIRCA system we have reported in this study could be used as a rapid screening method to facilitate such studies.

\section{ACKNOWLEDGEMENTS}

Supported by the governing board of University Hospital of Alexandroupolis and by Cyprus Foundation for Promotion of Research.

\section{Authors' affiliations \\ K Ritis, S Giaglis, N Spathari, A Micheli, D Tzoanopoulos, S Rafail, \\ V Papadopoulos, G Kartalis, First Division of Internal Medicine, Democritus University of Thrace, Alexandroupolis, Greece \\ D Zonios, A G Tzioufas, H M Moutsopoulos, Department of Pathophysiology, Athens University Medical School, Athens, Greece R Mean, Department of Biological Sciences, University of Cyprus C C Deltas, The Cyprus Institute of Neurology and Genetics, Nicosia, Cyprus}

\section{REFERENCES}

1 Livneh A, Langevitz P, Zemer D, Zaks N, Kees S, Lidar T, et al. Criteria for the diagnosis of familial Mediterranean fever. Arthritis Rheum 1997;40:1879-85.

2 Grateau G, Pecheux C, Cazeneuve C, Cattan D, Dervichian M, Goossens M, et al. Clinical versus genetic diagnosis of familial Mediterranean fever. Q J Med 2000;93:223-9.

3 Touitou I. The spectrum of familial Mediterranean fever (FMF) mutations. Eur J Hum Genet 2001;9:473-83.
4 The French FMF Consortium. A candidate gene for familial Mediterranean fever. Nat Genet 1997;17:25-31.

5 The International FMF Consortium. Ancient missense mutations in a new member of the RoRet gene family are likely to cause familial Mediterranean fever. Cell 1997;90:797-807.

6 Mulley J. The genetic basis for periodic fever. Am J Hum Genet 1999:64:939-42.

7 Centola M, Aksentijevich I, Kastner DL. The hereditary periodic fever syndromes: molecular analysis of a new family of inflammatory diseases. Hum Mol Genet 1998;7:1581-8.

8 Dode C, Pecheux C, Cazeneuve C, Cattan D, Dervichian M, Goossens M, et al. Mutations in the MEFV gene in a large series of patients with clinical diagnosis of familial Mediterranean fever. Am J Med Genet 2000;92:241-6.

9 Bernot A, da Silva C, Petit JL, Cruaud C, Caloustian C, Castet V, et al. Nonfounder mutations in the MEFV gene establish this gene as the cause of familial Mediterranean fever (FMF). Hum Mol Genet 1998;7:1317-25.

10 Sarrauste de Menthiere C, Terriere S, Pugnere D, Ruiz M, Demaille J, Touitou I. INFEVERS: the registry for FMF and hereditary inflammatory disorders mutations. Nucleic Acids Res 2003;31:282-5.

11 Deltas CC, Mean R, Rossou E, Costi C, Koupepidou P, Hadjiyanni I, et al. Familial Mediterranean Fever (FMF) occurs frequently in the Greek-Cypriot population of Cyprus. Genet Test 2002;6:15-21.

12 Goldrick MM, Kimball GR, Liu Q, Martin LA, Sommer SS, Tseng JY. NIRCA: a rapid robust method for screening for unknown point mutations. Biotechniques 1996;21:106-12.

13 Goldrick MM. RNase cleavage-based methods for mutation/SNP detection, past and present. Hum Mut 2001;18:190-204.

14 Jackson D, Hayden J, Quirke P. 1991 Extraction of nucleic acid from fresh and archival material. In: McPherson MJ, Quirke P, Taylor GR, eds. PCR: a practical approach, 1st ed. New York: Oxford University Press, 1991:30-2.

15 Ritis K Speletas M Tsironidou V, Pardali E, Kanariou M, Moschese V et al. Absence of Bruton's tyrosine kinase (Btk) mutations in patients with acute myeloid leukaemia. Br J Haematol 1998;102:1241-8.

16 Yates F. Contingency tables involving small numbers and the $\chi^{2}$ test. J R Stat Soc Suppl 1934;1:217-35.

17 La Regina M, Nucera G, Diaco M, Procopio A, Gasbarrini G, Notarnicola C, et al. Familial Mediterranean fever is no longer a rare disease in Italy. Eur J Hum Genet 2003;11:50-6.

18 Konstantopoulos K, Kanta A, Deltas C, Atamian V, Mavrogianni V, Tzioufas $A$, et al. Familial Mediterranean fever (FMF) associated pyrin mutations in Greece. Ann Rheum Dis 2003;62:479-81. 